\title{
ENTREVISTA COM O PROF. DR. JOSÉ BERNARDO BRILHA - Universidade do Minho - Portugal
}

\author{
Antonio Liccardo \\ aliccardo@uepg.br \\ PPG em Geografia, Universidade Estadual de Ponta Grossa, UEPG, Ponta Grossa, PR \\ Gilson Burigo Guimarães \\ gilsonburigo@gmail.com \\ Grupo Universitário de Pesquisas Espeleológicas, GUPE, Ponta Grossa, PR
}

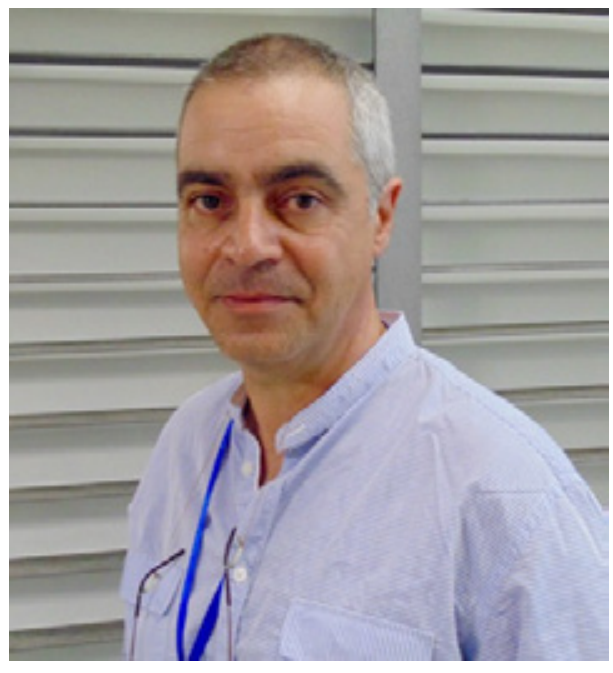

José Brilha é geólogo e professor catedrático da Universidade do Minho (Portugal). É membro da Equipe de Avaliação de Geoparques Mundiais da UNESCO, da Comissão Mundial de Áreas Protegidas da IUCN e do respetivo Grupo de Especialidade em Patrimônio Geológico e da Subcomissão de Sítios e Coleções Geológicas da IUGS. Foi fundador e editor-principal da revista científica Geoheritage, presidente da ProGEO (Associação Europeia para a Conservação do Património Geológico), membro do Comité Português para o IGCP e do Fórum Português de Geoparques. Atualmente leciona e desenvolve pesquisa em geodiversidade, geoconservação e geoparques.

Terr@Plural - Há muitos anos o senhor vem ao Brasil para proferir conferências, palestras ou ministrar cursos sobre Geodiversidade, Patrimônio Geológico, Geoconservação e Geoparques. No Brasil é considerado o grande precursor desta temática e acompanhou de perto a evolução que as pesquisas e discussões apresentaram. Como o senhor vê esta evolução brasileira e em que direção caminha?

O meu contato regular com o Brasil no que se refere a estes temas foi iniciado em 2006. Foi nesse ano que, por ocasião do $43^{\circ}$ Congresso Brasileiro de Geologia, em Aracajú, tive a oportunidade de conhecer a pequena comunidade brasileira que, então, se estava a iniciar nestes domínios. Em 12 anos, registra-se uma evolução acentuada da geoconservação no Brasil, em especial no meio acadêmico e científico. O número de alunos e pesquisadores em geoconservação aumentou muito, o que contribuiu para um incremento assinalável na produção de artigos, eventos científicos, dissertações de mestrado e, nos últimos anos, de teses de doutorado. Verificou-se também um alargamento, natural, desde a comunidade geológica, a colegas de geografia, em especial os que trabalham em geomorfologia, e a turismólogos. Aumentou o número de bolsas de doutorado e de pós-doutorado atribuídas 
por órgãos de fomento federal e estadual, o que vem demonstrar o aumento do reconhecimento da comunidade geocientífica pela área da geoconservação.

No entanto, esta evolução não teve o mesmo grau de desenvolvimento em outros níveis. Por exemplo, a gestão de unidades de conservação continua sem integrar ações de geoconservação, muitos sítios geológicos brasileiros, apesar de identificados pela SIGEP há anos, continuam sem qualquer estratégia de conservação e gestão e a formalização de um inventário nacional só agora começa a ser debatida. Porém, fiquei agradavelmente surpreendido pelo evento de há dias, organizado pelo Ministério Público Federal, onde ficou claro o interesse deste importante órgão federal pela proteção legal do património geológico brasileiro.

Noto que no Brasil os temas 'geoturismo' e 'geoparques' acabam por centrar muito da atenção dada à geoconservação. Sendo claramente tópicos que se enquadram no tema, penso, porém, que há espaço para serem desenvolvidos muitos outros trabalhos de base e que não estejam apenas direcionados para o geoturismo e geoparques. No último Simpósio Brasileiro de Patrimônio Geológico, realizado em 2017 em Ponta Grossa, constatei que a qualidade geral dos trabalhos foi superior à de eventos anteriores, o que é um excelente sinal de maturidade da comunidade científica e académica brasileira!

Terr@Plural - Na Europa, e em Portugal especialmente, parece que a Geoconservação alcançou um status elevado, como uma parte importante ou mesmo uma disciplina moderna das Geociências. Na sua opinião isto ocorre como fenômeno localizado na Europa, por sua conjuntura específica, ou é um processo mais amplo que alcançará países em desenvolvimento?

Verifica-se, um pouco por todo o mundo, a introdução da geoconservação em planos de estudo de cursos de graduação e de pós-graduação. Na Universidade do Minho temos oferta de pós-graduação específica e focada em geoconservação, desde 2005, mas esta é uma situação ainda não muito alargada a outros países. Todavia, existem hoje estudantes de mestrado e doutorado em muitos países a desenvolverem pesquisa em áreas temáticas relacionadas com geoconservação. No entanto, preocupa-me a escassez de emprego para os especialistas em geoconservação que se estão a formar nas universidades. O setor público, que tem a responsabilidade de implementar políticas de conservação da natureza e ordenamento do território, não entendeu ainda que o paradigma destas políticas está a mudar e que devem ser incluídas novas ideias e novas ações.

A criação da recente Comissão de Patrimônio Geológico na IUGS, a existência de dois mecanismos de reconhecimento de patrimônio geológico por parte da UNESCO (sítios de patrimônio mundial e geoparques mundiais), a publicação de revistas científicas internacionais dedicadas à geoconservação, a existência de sessões temáticas no Congresso Internacional de Geologia e em inúmeros outros eventos científicos internacionais, nacionais e regionais, são, para mim, exemplos claros que a geoconservação é, sem dúvida, uma nova disciplina das geociências. A juntar a isto refiro as recentes iniciativas que estão a ser levadas a cabo pelos serviços geológicos dos países latino-americanos para se desenvolver o inventário de patrimônio geológico destes países. Igualmente, a geoconservação 
é um dos tópicos que está hoje a ser usado em programas de formação de geólogos que trabalham em serviços geológicos de África. Há muitos exemplos que ilustram como a geoconservação está, cada vez mais, a implementar-se a diversos níveis.

Terr@Plural - Aparentemente há um desequilíbrio geográfico ou geopolítico na distribuição de geoparques no mundo. Percebe-se uma grande concentração na Europa e China e pouquíssimos geoparques no Hemisfério Sul, especialmente em países onde o papel social destes projetos traria grandes benefícios. No Brasil, após o Geoparque Araripe, muitos projetos foram aventados, mas ainda nenhum deles se tornou uma realidade. Com base em sua experiência, quais as perspectivas entre os projetos que conhece no Brasil e como o senhor vê a possibilidade de crescimento do programa da UNESCO na América do Sul?

A América do Sul tem tudo para que o conceito 'geoparque' possa ser implementado com sucesso e com os princípios que agora estão consagrados no Programa Internacional Geociência e Geoparques da UNESCO. É verdade que a criação de novos geoparques na América do Sul tem sido mais lenta do que o esperado. O caso do Brasil é paradigmático. Depois de um arranque, de alguma forma inesperado, com a criação do Geoparque Araripe em 2006 e respetiva entrada na Rede Global de Geoparques, seria de esperar que, 12 anos depois, existissem hoje muito mais geoparques brasileiros.

Há, certamente, diversas razões que explicam esta dificuldade de concretização de geoparques no Brasil, mas parece-me que esta reflexão tem de ser feita, em primeiro lugar, pela comunidade geocientífica brasileira. Sendo estrangeiro, não sou a melhor pessoa para fazer esta análise que, obrigatoriamente, tem de estar baseada num profundo conhecimento da realidade brasileira, a nível cultural, social, político e administrativo. Gostaria de salientar, porém, que a estratégia de gestão territorial conhecida por 'geoparque' tem suficiente maleabilidade para poder ser implementada em qualquer país do mundo, sem perda do essencial e mantendo os objetivos que a caracterizam.

Quero com isto dizer que o Brasil, como qualquer outro país, tem todas as condições para criar e implementar geoparques com enorme possibilidade de serem reconhecidos pela UNESCO e com potencial para serem boas referências internacionais.

Terr@Plural - A influência da Escola Portuguesa no Brasil a respeito de conceitos ligados à geodiversidade é enorme, o que se deve aos fatores de língua e cultura, mas também em função do desenvolvimento que Portugal apresentou nesta área nas últimas décadas. Quais foram os benefícios e quais as perspectivas desta conexão?

Não sei bem se existe uma 'Escola Portuguesa' relativa aos temas da geodiversidade e da geoconservação, penso que os trabalhos e iniciativas que temos implementado em Portugal vão na linha das grandes tendências internacionais. Tentamos sempre ver o que se faz de melhor a nível internacional, verificar se tem aplicação à realidade portuguesa e apostar em dar o nosso contributo para desbravar, pouco a pouco, esta área científica.

Em Portugal, os trabalhos em geoconservação, realizados de forma mais sistemática, têm cerca de 20 anos. Nessa altura, sabíamos muito pouco sobre o tema e, por isso, a 
nossa estratégia foi aprender, ver o que se fazia em outros países e integrarmo-nos na comunidade internacional. Em ciência, nada se faz se estivermos sozinhos; temos de usar a mesma linguagem, os mesmos métodos, porque só assim conseguimos participar na discussão e contribuir com o nosso trabalho para o esforço internacional de desenvolver a geoconservação.

Hoje, a quantidade de bibliografia que existe sobre geoconservação é vasta e em diversas línguas. Tenho reparado que, em diversos países e também no Brasil, há pessoas que estão a contatar com a geoconservação pela primeira vez, fascinadas pelo tema, mas que não "entram a sério" na bibliografia internacional. O resultado é, por vezes, produzirem-se trabalhos que parecem querer "reinventar a roda", ou seja, voltam a abordar conceitos e temas que a comunidade internacional já debateu há diversos anos e que hoje já estão consagrados.

Penso também que, no Brasil, há um problema no ensino da língua inglesa na escola pública e um reduzido contato com esta língua no dia-a-dia que faz com que, a generalidade dos estudantes, tenha baixa competência no domínio do inglês, o que acaba por provocar um reduzido nível de utilização da bibliografia internacional. Tenho um exemplo bem ilustrativo desta situação: o livro que publiquei em 2005 e que hoje tem um interesse essencialmente histórico porque muitas das ideias desse tempo estão hoje completamente ultrapassadas, continua a ser largamente usado por estudantes brasileiros de mestrado e doutorado, apenas porque está escrito em português.

A geoconservação evoluiu muito nos últimos dez anos, há que consultar sempre a bibliografia mais recente, a menos que se queira fazer um histórico da evolução das ideias em geoconservação!

Terr@Plural - A Geoconservação, como campo de investigação científica e de atuação profissional nas Ciências da Terra, deve se alicerçar em conceitos-chave, tais como geodiversidade, patrimônio geológico, geoparque ou geoturismo. Entretanto ainda são constatadas divergências. Por exemplo, o conceito de geoturismo deve estar baseado em áreas de relevância geológica ou deve ter uma conotação geográfica? O patrimônio geológico deve ser entendido como uma modalidade de geopatrimônio? Em sua opinião, existe um descompasso na apropriação destes conceitos?

Já me referi à importância de usarmos uma mesma linguagem, se nos queremos inserir numa comunidade. Só integrando a comunidade internacional da geoconservação poderemos aprender e dar o nosso contributo para o desenvolvimento desta área geocientífica. Claro que, em ciência, podemos e devemos ser críticos. Mas hoje, a nível internacional, tal como já não há discussões sobre o significado dos termos 'granito' ou 'amonite', por exemplo, não me parece que seja muito relevante voltar a discutir termos base da geoconservação que têm mais de 60 anos.

A questão do geopatrimônio é, para mim, um exemplo deste ponto. Em todo o mundo, o termo geoheritage significa património geológico desde há várias décadas. Hoje, instituições internacionais e de referência como a UNESCO, a IUCN, a IUGS, entre outras, têm este entendimento. A tradução direta para português deste termo é, obviamente, geopatrimônio 
e, por isso, ambos os termos têm que ter o mesmo significado. A palavra granite, em inglês, e granito, em português, significam o mesmo, como é óbvio. Tenho muita dificuldade em aceitar que geoheritage e geopatrimônio não tenham o mesmo significado, tal como defendem alguns colegas do Brasil e de Portugal. Assim, para mim, geopatrimônio é simplesmente a versão curta de património geológico e não uma designação que discrimina os vários tipos de património abiótico.

Apesar da evolução registrada na geoconservação nas últimas duas décadas, trata-se ainda de uma área com poucos especialistas e com enorme potencial de amadurecimento. A única maneira de fazermos avançar este tema, que tem ramificações para diversos outros domínios, é construir redes, nacionais e internacionais, juntando especialistas com diversas formações (geólogos, geógrafos, turismólogos, antropólogos, economistas, gestores, sociólogos, etc.), usando uma terminologia e princípios comuns. Como somos poucos, precisamos aumentar a nossa massa crítica, de modo a ganhar força suficiente para conseguirmos implementar a geoconservação na sociedade. 